\title{
Identifying the pitfalls for social interaction in computer-supported collaborative learning environments: a review of the research
}

\author{
Karel Kreijns ${ }^{\mathrm{a}, *}$, Paul A. Kirschner ${ }^{\mathrm{b}}$, Wim Jochems ${ }^{\mathrm{b}}$ \\ ${ }^{a}$ Faculty of Technical Sciences, Open University of the Netherlands, PO Box 2960, 6401 DL Heerlen, \\ The Netherlands \\ ${ }^{\mathrm{b}}$ Educational Technology Expertise Center, Open University of the Netherlands, PO Box 2960, \\ 6401 DL Heerlen, The Netherlands
}

\begin{abstract}
Computer-mediated world-wide networks have enabled a shift from contiguous learning groups to asynchronous distributed learning groups utilizing computer-supported collaborative learning environments. Although these environments can support communication and collaboration, both research and field observations are not always positive about their working. This article focuses on factors which may cause this discrepancy, centering on two pitfalls that appear to impede achieving the desired results, namely taking for granted that participants will socially interact simply because the environment makes it possible and neglecting the social (psychological) dimension of the desired social interaction. It examines the social interactions which determine how groups develop, how sound social spaces characterized by group cohesion, trust, respect and belonging are established, and how a sense of community of learning is established. It concludes with an evaluation of educational techniques proposed by instructors and educators, as well as the findings of educational researchers and guidelines for avoiding the pitfalls.

(C) 2003 Elsevier Science Ltd. All rights reserved.

Keywords: Collaboration; Computer-supported collaborative learning; Social interaction
\end{abstract}

There is ample empirical evidence that cognitive processes necessary for deep learning and information retention occur in dialogues (Van der Linden \& Renshaw, 2001). However, research on group learning shows that asynchronous distributed learning groups (DLGs) utilizing computer supported collaborative learning

\footnotetext{
* Corresponding author.

E-mail address: karel.kreijns@ou.nl (K. Kreijns).
} 
(CSCL) environments often lack the social interaction needed for these dialogues. Hallett and Cummings (1997) observe that by "having the majority of assignments in public forums with the entire class posting at a given time, and with numerous prompts and encouragement from the instructor, it was hoped that interaction among students would occur naturally. This was not what took place"' (p. 105).

Gunawardena (1995) explains the negative experiences from her observations in computer conferences where "the social interactions tend to be unusually complex because of the necessity to mediate group activity in a text based environment. Failures tend to occur at the social level far more than they do at the technical level" (p. 148). Hobaugh (1997) emphasizes that problems with social dynamics amongst group members is often the major cause of ineffective group actions in a distance learning environment. These observations stress the necessity of taking a closer look at the social and social psychological aspects of collaborative learning and how they can be supported.

Why then have educators apparently not 'walked the extra mile' to support these social (psychological) aspects? Our premise is that the shift from contiguous learning groups to asynchronous distributed learning groups has fallen prey to two major pitfalls. The first is taking for granted that social interaction automatically takes place just because an environment makes it technologically possible. The second is the tendency to restrict social interaction to educational interventions aimed at cognitive processes while social (psychological) interventions aimed at socio-emotional processes are ignored, neglected or forgotten.

Although these pitfalls are not uniquely related to CSCL environments, the nature of these environments have made them more salient and critical than in face-to-face settings. The special nature of computer-mediated communication subsystems embedded in the CSCL environment (e.g. text-based e-mail, forums, chat) affects the type of messages exchanged and how the messages are interpreted (Daft \& Lengel, 1984; Daft, Lengel, \& Trevino, 1987). This appears to alter interpersonal communication (Rice, 1992; Short, Williams, \& Christie, 1976) and consequently also the development of both interpersonal relationships and groups (Culnan \& Markus, 1987; Walther, 1996; Walthers, Anderson, \& Park, 1994). In addition, CSCL environments are used predominantly during task execution, excluding social, off-task communication. Finally, group members are often unacquainted to each other and have 'zero-history'. These aspects are normally not present in face-to-face settings.

\section{Collaborative learning}

There seems to be an almost irresolvable discussion as to what 'collaborative' and 'cooperative' learning are and what their differences/commonalities are. This is confounded by the fact that educational researchers often have different purposes, goals, and perspectives (e.g. whether the terms denote processes or states) which prohibit a clear distinction between the two approaches to group learning. Panitz (1996) sees collaboration as a philosophy of interaction and personal lifestyle and cooperation as a structure of interaction designed to facilitate accomplishment of an end product or goal through people working together in groups. Slavin (1997) 
associates cooperative learning with well-structured knowledge domains and collaborative learning with ill-structured knowledge domains. Roschelle and Teasley (1995) state that: "Cooperation is accomplished by the division of labour among participants, as an activity where each person is responsible for a portion of the problem solving...", while collaborative learning involves the "... mutual engagement of participants in a coordinated effort to solve the problem together" (p. 70). This perspective is supported by Lethinen, Hakkarainen, Lipponen, Rahikainen, and Muukkonen (1999) who see the distinction based on different ideas of the role and participation of individual members in the activity.

The debate is still going on and it is beyond the scope of this article to state which definition or perspective is most appropriate. It is, however, more important to stress that there are far more similarities than differences between the two (Kirschner, 2001). Kirschner notes that in both:

- learning is active;

- the teacher is usually more a facilitator than a "sage on the stage";

- teaching and learning are shared experiences;

- students participate in small-group activities;

- students must take responsibility for learning;

- students are stimulated to reflect on their own assumptions and thought processes; and

- social and team skills are developed through the give-and-take of consensusbuilding;

Since there are far more commonalities than differences we consider the two-for argument's sake - to be equivalent and use the term "collaborative" in the rest of this contribution.

\subsection{Collaborative learning and social interaction}

Collaborative learning leads to deeper level learning, critical thinking, shared understanding, and long term retention of the learned material (e.g. Garrison, Anderson, \& Archer, 2001; Johnson \& Johnson, 1999). It also provides opportunities for developing social and communication skills, developing positive attitudes towards co-members and learning material, and building social relationships and group cohesion (Johnson \& Johnson, 1989, 1999). These effects are reinforced when collaborative learning is applied to ill-structured, complex tasks embedded in an authentic context, that since such conditions also increase the effectiveness of social construction of knowledge (Jonassen, 1991, 1994) and enable the development of competencies (Keen, 1992). Competencies are abilities that enable learners to recognize and define new problems in their domain of study and-future-work as well as solve these problems (Kirschner, van Vilsteren, Hummel, \& Wigman, 1997).

Although a number of variables (e.g. group size, group composition, nature of task, learning styles) have been identified as factors which potentially influence the effectiveness of collaborative learning, all these factors are related in one way or 
another to one single key element: social interaction. Hooper and Hanafin (1991) studying the effects of group composition on learning found for example that "achievement differences attributable to group composition correspond to differences in intra-group interaction" (p. 28) and conclude that "the nature of intragroup cooperation is potentially of greater importance than group composition per se" (p. 28). Hiltz (1994) underlined the importance of social interaction stating that "the social process of developing shared understanding through interaction is the 'natural' way for people to learn" (p. 22). The belief that social interaction is a key element in group learning is shared by many (distance) educational researchers. Gilbert and Moore (1998), Gunawardena (1995; Gunawardena, Lowe, Constance, \& Anderson, 1997), Liaw and Huang (2000), Northrup (2001), and Wagner (1994, 1997) confirm the notion that social interaction is a conditio sine qua non for learning.

Social interaction appears to be the key to collaboration. If there is collaboration then social interaction can be found in it, and vice versa, if there is no social interaction then there is also no real collaboration (Garrison, 1993; Johnson, Johnson, and Stanne, 1985; Soller, Lesgold, Linton, \& Goodman, 1999).

\subsection{Enhancing collaborative learning}

Just placing students in groups does not guarantee collaboration (Brush, 1998; Johnson \& Johnson, 1989, 1999; Soller, 1999). The incentive to collaborate has to be structured within the groups. A complex of simultaneously applied instructional approaches, each reinforcing and/or complementing the other can enhance collaborative learning and social interaction amongst group members. All these instructional approaches result in group members socially interacting in ways that encourage elaboration, questioning, rehearsal, and elicitation. We discuss three approaches: (1) the cognitive approach of promoting 'epistemic fluency', (2) the direct approach of structuring task-specific learning activities, and (3) the conceptual approach of applying a set of conditions to stimulate/stress collaboration.

\subsection{Cognitive approach: promoting epistemic fluency to take place}

The cognitive approach is aimed at specific activities in the learning task that promote 'epistemic fluency'. Morrison and Collins (1996) define epistemic fluency as "the ability to identify and use different ways of knowing, to understand their different forms of expression and evaluation, and to take the perspectives of others who are operating within a different epistemic framework" (p. 109). Epistemic fluency can be achieved by applying a set of epistemic tasks within the group learning tasks (Ohlsson, 1996) including describing, explaining, predicting, arguing, critiquing, evaluating, explicating and defining - all in the context of a discourse.

\subsection{Direct approach: structuring a task specific learning activity}

The direct approach involves the use of specific collaborative techniques that structure a task specific learning activity (e.g. writing a report). These are very spe- 
cific and well-defined techniques that teachers can learn and apply quickly and are often focused on specific subject areas and grade levels. Each specific collaborative technique can be used as a template for adaptation to a slightly different learning activity. Examples of the direct approach are Student Teams-Achievement Divisions (Slavin, 1986), Jigsaw (Aronson, Blaney, Stephan, Silkes, \& Snapp, 1978; Slavin, 1990) and Structured Academic Controversy (Johnson \& Johnson, 1993). For an analysis of the different methods see Johnson et al. (1985).

\subsection{Conceptual approach: applying a set of conditions that enforce collaboration}

The conceptual approach involves tailoring a general conceptual model of collaborative learning to the desired or chosen circumstances such that specific types of collaboration can be created and/or enforced (Johnson \& Johnson, 1989, 1999). Conceptual methods are not easily learned, can be used in any subject area for any age student, and are highly adaptable to changing conditions Examples of the conceptual approach are Learning Together (Johnson \& Johnson, 1999), Group Investigation (Sharan \& Sharan, 1976, 1992), and Constructive Controversy (Johnson \& Johnson, 1979). The conceptual approach usually makes use of:

- Positive interdependence: team members are linked to each other in such a way that each team member cannot succeed unless the others succeed and/or that each member's work benefits the others (and vice versa).

- Promotive interaction: individuals encourage and help each other's efforts so as to in order to reach the group's goals.

- Individual accountability: all group members are held accountable for doing their share of the work and for mastery of all of the material to be learned.

- Interpersonal and small-group skills: specific skills are needed when learners are learning within a group; students who have not been taught how to work effectively with others cannot be expected to do so must be developed (Sharan \& Sharan, 1992).

- Group processing: the group determines which behaviors should continue or change for maximizing success based upon reflection of how the group has performed so far.

Although the conditions are listed separately, they are highly related to each other. For example, positive interdependence results in promotive interaction; and promotive interaction requires group members to possess small-group skills. If the conditions are met, this approach will increase the learner's effort exerted to achieve, the quality of relationships among participants, and the participants' psychological health (Johnson \& Johnson, 1989).

Not only does this promote positive effects, it also reduces the negative effects usually present in non-collaborative groups such as the free-rider or hitchhiking effect, social loafing, and the sucker effect. The free-rider or hitchhiking effect (Kerr \& Bruun, 1983) exists when "group members exert less effort as the perceived dispensability of their efforts for the group success increases" (p. 78). In other words, 
they feel that the group is doing enough and that they don't have to contribute. Social loafing (Latané, Williams, \& Harkins, 1979) exists when group members exert less effort as the perceived salience of their efforts for the group success decreases. In other words, as the group size increases so does the anonymity and the non-participation. The social loafer differs from the free rider in that the former lacks the motivation to add to the group performance, while the latter tries to profit from others while minimizing essential contributions. Finally, the sucker effect (Kerr, 1983) exists when the more productive group members exert less effort as the awareness of co-members free-riding increases. That group refuse to further support noncontributing members (they refuse to be 'suckers') and therefore reduce their individual efforts.

\section{Social interaction in CSCL environments}

If it is so evident that social interaction is a prerequisite for collaboration and collaborative learning, why then do educators, instructors and designers often appear not to pay the needed attention to it when using or designing CSCL environments? There appear to be at least two factors identifiable which can be seen as pitfalls to social interaction.

\subsection{Pitfall 1: Taking social interaction for granted}

According to Kearsley (1995), social interaction in CSCL environments must be organized or it is unlikely to occur or be meaningful. Liaw and Huang (2000) and Northrup (2001) determined that in a learning environment, interaction does not just happen, but must be intentionally designed into the instruction. If we discount the problem that most educators do not know what they have to do in order to encourage social interaction (Kearsley, 1995; Rourke, 2000a), what remains is the observation that a majority of educators - consciously or unconsciously-takes social interaction for granted. They think that because in face-to-face learning groups social interaction is 'easy' to achieve if not already there, the same patterns will be encountered in distributed learning groups. Rourke (2000b), however, concluded that social interaction can no more be taken for granted in computer conferences than it can be in face-to-face settings such as lecture halls or small seminar settings.

This leads us to the first pitfall, namely taking for granted that social interaction will automatically occur just because it technology allows it. Although CSCL environments allow a certain degree of social interaction to take place, it is no more a matter of course than it is in face-to-face settings. Organizational researchers such as Olson and Olson (2000) note that "with the invention of groupware, people expect to communicate easily with each other and accomplish difficult work even though they are remotely located or rarely overlap in time" (p. 139). Wagner (1994) concludes that the "growing 'folk' acceptance of a causal relationship between system interactivity [the degree a system allows for interaction] and instructional inter- 
action has placed an unrealistic expectation on interactive technologies to ensure that instructional interaction do occur"' (p. 8).

Also, the use of CMC itself introduces barriers not present in face-to-face settings. First, it differs from face-to-face with respect to media richness: "the medium's capacity for immediate feedback, the number of cues and senses involved, personalization, and language variety" (Rice, 1993, pp. 452-453). Learners rate text-based $\mathrm{CMC}$ as low in media richness, because it constrains both their vocabulary for expressive and the direct communication for accomplishing certain tasks such as decision making. Learners rated face-to-face communication to be the most media rich . Media-poor, text-based CMC impacts the level of communication and, thus, social interaction (Daft \& Lengel, 1984; Daft et al., 1987).

Furthermore, the use of text-based CMC can cause oral and written communication apprehension, potentially retarding social interaction (Berge, 1997; Fishman, 1997). McCroskey (1977) defined communication apprehension as "an individual's level of fear or anxiety associated with either real or anticipated communication with another person or persons" (p. 78). This apprehension, finally, may influence the degree of social interaction (Muirhead, 1999).

Therefore, just providing members of a distributed learning group with more communication media than they already have (but possibly with characteristics that make these more appropriate for certain kinds of communication activities which require social interaction) neither necessarily fosters nor ensures social interaction. Although these media can contribute to a more suitable condition for the execution of the communication tasks, they do not guarantee that the desired social interaction will take place. In other words, availability of communication media is necessary, but not sufficient.

\subsection{Pitfall 2: Restricting social interaction to cognitive processes}

Educators recognizing the first pitfall often tend to limit their actions to the task context (tightly related to the collaborative execution of learning tasks) and the educational dimension (where social interaction solely in service of the cognitive processes or other educational purposes). This, however, might not be enough. Rourke (2000b) remarks that "if students are to offer their tentative ideas to their peers, if they are to critique the ideas of their peers, and if they are to interpret others' critiques as valuable rather than as personal affronts, certain conditions must exist. Students need to trust each other, feel a sense of warmth and belonging, and feel close to each other before they will engage willfully in collaboration and recognize the collaboration as a valuable experience" ( $(\mathbf{q}$ 2). He emphasizes that in order to elicit these conditions students need to trust each other, feel a sense of warmth and belonging, and feel close to each other before they will engage willfully in collaboration. Northrup (2001), Gunawardena (1995), and Cockburn and Greenberg (1993) stress the need for relationship building and sharing a sense of community and a common goal. Finally, Wegerif (1998) noted that "forming a sense of community, where people feel they will be treated sympathetically by their fellows, seems to be a necessary first step for collaborative learning. Without a feeling of commu- 
nity people are on their own, likely to be anxious, defensive and unwilling to take the risks involved in learning" (p. 48).

This suggests a social (psychological) dimension to the social interaction in collaborative learning which relates to the socio-emotional aspects of group forming and group dynamics. In other words, it relates to processes that have to do with getting to know each other, committing to social relationships, developing trust and belonging, and building a sense of on-line community. These processes are not directly related to the task in the strict sense. If group members are initially not acquainted with each other and the group has zero-history (which is often the case in distance education institutions), group forming, developing a group structure, and group dynamics are essential to developing a learning community. Contemporary CSCL environments may not provide adequate opportunities for social interaction, the development of friendships and camaraderie (Clark, 2000; Hiltz, 1997, 1998). Fig. 1 depicts the educational and the social (psychological) dimension of social interaction.

Wegerif (1998) emphasizes the point that "many evaluations of asynchronous learning networks understandably focus upon the educational dimension, either learning outcomes or the educational quality of interactions, overlooking the social dimension which underlie this" (p. 34). Adapting Gilroy's (2001) formula we conclude that:

\section{Valued Learning Experience $=\mathrm{F}$ [Pedagogy, Content, Community]}

If any one of the three variables approaches zero, the function also approaches zero. This means that we need all the three variables to exist at the same time, i.e. a functional pedagogy for instruction, relevant content to be learned, and a working community of learning. Otherwise the learning experience will be low or non-existent.

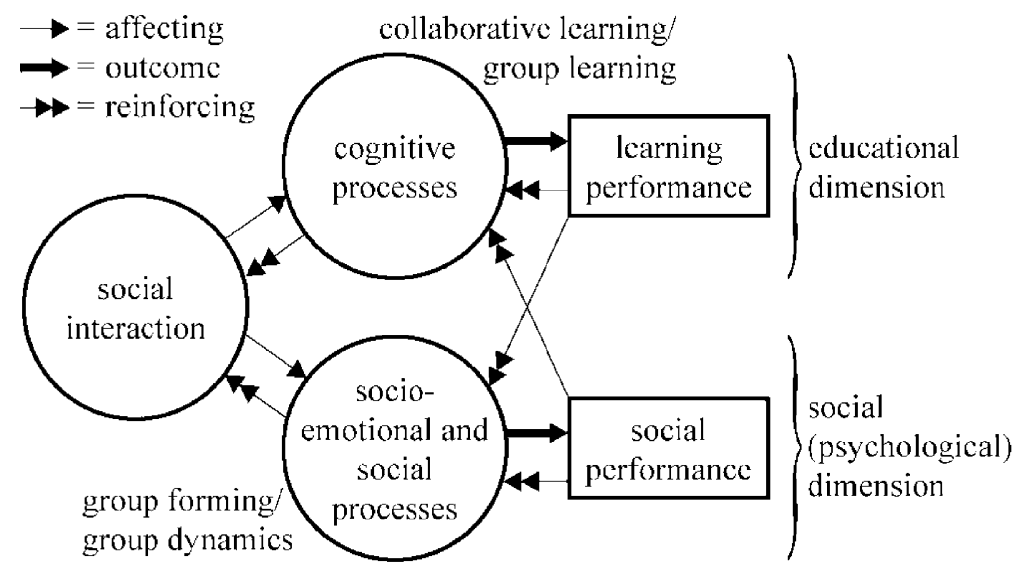

Fig. 1. The two functions of social interaction. 
The validity of this formula is, for example, supported by Jehng (1997) who found the psycho-social processes underlying collaborative interactions to be an important factor impacting learning. Liaw and Huang (2000) found that social and interpersonal interaction can directly foster the interaction between content and instruction. This 'objective' effect is compounded by the more 'subjective' effects found by Zhang and Fulford (1994) and Northrup (2001) who suggest that students' perception of the efficacy of social interaction can have significant effects on learning outcomes.

This brings us to a second pitfall, namely restricting social interaction to the cognitive processes in learning and ignoring or forgetting the importance of the social (psychological) dimension of social interaction for group forming, group structure, and group dynamics, all of which are necessary for building learning communities. This is what McGrath (cited in McConnell, 1994) calls the "member support and group well being functions' which are so important for successful technology-mediated group-work, but which are often neglected, or worse, never considered (p. 61).

\section{Community building in CSCL environments}

A community needs an affective structure. Building an affective structure entails a process of affiliation, impression formation, and interpersonal attraction to induce and promote social relationships and group cohesion. Affiliation is the propensity people have to get in contact with others. Affiliation will occur if group members perceive that they are mutually dependent on each other to successfully accomplish the working- and learning tasks leading them to get in contact with each other. Impression formation is a social cognitive process where individuating impressions of the others in a group are developed, i.e. 'getting to know one another'. Each group member must develop individuating impressions of the co-members. Based upon these impressions, social work-relationships with the other group members can be developed. The nature of the social relationship is, amongst other things, determined by the attractiveness of the co-member. Attractiveness is the feeling a group member has about other group members and is influenced by affection, status, and competence.

Ultimately, social relationships contribute to group cohesion, common understanding, an orientation towards cooperation and the desire to remain in their group. An important attribute of group cohesion is mutual trust amongst group members: the cognitive and affective assurance that group members respect each others' interests and, therefore, can orient themselves towards each others' words, actions, and decisions with an easy conscience (Emans, Koopman, Rutte, \& Steensma, 1996). Social relationships, group cohesion, and trust define the affective structure in the social space that in turn reinforces social interaction. The next two sub-sections investigate two factors influencing the building of communities in CSCL environments.

\subsection{Non-task contexts and social interaction in the social (psychological) dimension}

Although, social and social psychological processes can be initiated in task contexts, we conjecture that non-tasks contexts will foster these processes more than 
task contexts can. This is because non-task contexts are usually characterized by informal and casual conversations - often initiated by impromptu encounterswhich deal with a broad range of (task and non-task) subjects allowing serendipitous opportunities for getting acquainted. These conversations show an abundant exchange of socio-emotional and affective information contributing to impression formation, creation of social relationships, group cohesion and a sense of community. Gilbert and Moore (1998) argue that "social interaction between students and teachers and between students and students can sometimes have little to do with instructional learning, but can still help to create a positive (or a negative) learning environment" (p. 30). Similarly Northrup (2001) contends that through social interaction "the opportunity for learning more about peers and connecting them in non-task specific conversation is more likely to occur. Although social interaction may have very little to do with a course, it is still valued as the primary vehicle for student communications in a Web-based learning environment." (p. 32). Rovai (2001) lent support to these hypotheses when he found evidence that "community was stronger in the program that provided learners more and diverse [non-task] opportunities to interact with each other and that the most important community components in which groups differed were spirit and trust" (p. 105). In sum, the presence of non-task contexts positively affects the building of an affective structure and, thus, on the building of communities. However, contemporary CSCL environments usually do not provide such non-task contexts.

\subsection{Interpersonal effects of using computer-mediated communication}

Social psychological and organizational communications research report negative effects of CMC on impression formation and relational communication behavior (e.g. Rice, 1993; for a review see Garton \& Wellman, 1995; Walther et al., 1994). This may in turn negatively influence the creation of a productive social space for working in groups. One of the factors contributing to impression formation is the exchange of nonverbal cues conveying socio-emotional and affective information. These cues are usually transmitted by vision (e.g. facial expressions, posture, gaze and gestures), olfaction (e.g. use of Cologne/perfume, body odor), and/or audition (e.g. voice volume, inflection and tone). Based on these cues, learners develop individuating impressions of fellow group members. Since CMC is text-based, it cannot transfer this kind of information. Short et al., (1976) note that in "most cases, the functions of the non-verbal cues have been in some way related to forming, building or maintaining the relationships between the interactants. The absence of the visual channel reduces the possibilities for expression of socio-emotional material and decreases the information available about the other's self-image, attitudes, moods and reactions. So, regarding the medium as an information transmission system, the removal of the visual channel is likely to produce a serious disturbance of the affective interaction ..." (p. 59-60).

Additionally, Sproull and Kiesler (1986, see also Kiesler, Siegel, \& McGuire, 1984) argue that $\mathrm{CMC}$ also inhibits the transfer of social context cues that provide static information about physical environment and hierarchical status (e.g. where the interactant is, the objects/artifacts that can be found there, the clothes the inter- 
actant is wearing) as well as dynamic information (e.g. what the interactant was just doing, who else is also in the room). They claimed that this reduction of social context cues deters interpersonal impressions. The note that "without nonverbal tools, a sender cannot easily alter the mood of the message, communicate a sense of individuality, or exercise dominance or charisma. ... Communicators feel a greater sense of anonymity and detect less individuality in others" (p. 48).

Consequently, social relationships are not likely to emerge and the creation of a common social space is hampered. Furthermore, if individuating impressions cannot be developed, the resulting communication behavior may negatively influence communication activities. In this light, CMC has been characterized as impersonal, unfriendly, task-oriented, anonymous and has sometimes even been accused of leading to disinhibited behavior (Sproull \& Kiesler, 1986). This could render CMC systems unsuitable for certain communication activities and may affect group-problem solving effectiveness (Hiltz, Johnson, \& Turoff, 1986).

One theory that accounts for these effects is social presence theory (Short et al., 1976) which characterizes communication media in terms of their potential to communicate socio-emotional cues such that the 'other' is perceived as physically salient and present. Other researchers see social presence as not solely a quality of the medium itself, but also of the user's perception of the medium. Here, social presence becomes synonymous with social climate or social space (Gunawardena, 1995; Rourke, Anderson, Archer, \& Garrison, 1999). Researchers generally agree that the less channels that are available to communicate cues, the less social presence communicators will experience resulting in the experiencing of CMC as impersonal (Walther et al., 1994, p. 7).

Walther (1992), however, doubts the implications made by social presence theory. He argues that research has not taken into account the effects of the time needed to accumulate the socio-emotional cues needed to develop an individuating impression. He (Walther, 1993) elaborates this by stating that "time limitations in computer conferencing experiments may preempt normal social cognitive patterns of impression development and the interpersonal communication which results from such impressions" (p. 385). Therefore, the negative outcomes predicted by social presence theory, are indeed going to be found in these settings. He found that the transmission of socio-emotional cues and other patterns of communication occur at a significantly lower rate in CMC than they do in face-to-face communication. Thus, if time limitation plays no role, the same personal impressions will be developed in CMC. In other words, time appears to be an important factor which positively affects development of an affective structure and, therefore, community building. If we take into consideration that even face-to-face groups need time for group forming and establishing an affective structure (Forsyth, 1990; Hobaugh, 1997) the 'time' we are talking about here, is- in fact- extra time needed due to the limitations of CMC.

\section{Avoiding the pitfalls}

Adding all of this up, we must agree with Brush (1998) that "research specifically investigating the effects of collaborative learning with advanced computer-based 
instruction such as ILSs [Integrated Learning Systems] is limited and does not provide a great deal of insight into the methods with which collaborative learning strategies can be effectively integrated into ILS activities" (p. 11). Rourke (2000a) concludes that there is a paucity of theories, tools and cumulative results upon which to build.

We discern four categories of suggestions from current educational research aimed at alleviating the two pitfalls, namely research on (1) collaborative learning methods, (2) interactivity in web-based CSCL environments, (3) the instructor's and/or learners' role, and (4) social presence. The categories are not necessarily independent.

\subsection{Using collaborative learning methods in DLGs}

Some educational researchers draw on the same approaches for collaborative learning that have been shown to be successful in traditional learning groups. Brush (1998), for example, suggests instituting measures which support positive interdependence, individual accountability, and collaborative skills. To support positive interdependence through group roles, Brush suggests consistently prompting and reminding the group members of their roles throughout the learning activity. Soller et al. (1999) focus on collaborative learning conversation skills aimed at promoting epistemic fluency, using a sentence opener-based communication interface with sentence openers like 'To justify...' and 'Can you explain how ...' This way, they explicitly enforce effective peer interaction to happen.

These suggestions assume that groups have already reached the stage of becoming a performing group, that is, that all members know each other, that there is group cohesion, and that members are willing to help each other. This stage, however, is difficult to reach in distributed learning groups, despite modern CSCL environments. In other words, fostering group cohesion in CSCL is more difficult than maintaining it. Collaborative learning methods can potentially support the social (psychological) processes. For this reason, Hiltz (1998), observing that potential negative effects of online courses appear to be a loss of social relationships and a sense of community, suggests using collaborative learning strategies for this.

\subsection{Building interactivity into web-based CSCL environments}

Another group of researchers specifically focuses on improving interactivity in web-based CSCL environments. Interactivity is the degree a delivery technology is capable of establishing a two-way connection between distributed participants for the exchange of audio, video, text and graphical information (Wagner, 1994). Zhang and Fulford (1994) distinguish interactivity that relates to learner-content interaction and interactivity that relates to social interaction outside the instructional context (social interaction in the social (psychological) dimension). This corresponds with our two functions of social interaction depicted in Fig. 1.

Gilbert and Moore (1998) use the term social interaction for the socio-emotional and affective exchanges between learners in the task context and instructional interaction for learner-content interaction. They state that "it is important to distinguish 
between interactivity which is primarily social in nature and interactivity which embraces key instructional objectives" (p.31), thus in line with Zhang and Fulford (1994). Within the context of social and instructional interaction, Northrup (2001) propose a framework of interaction attributes; each embedding possible strategies and tactics that can be used to facilitate instructional and social interactivity. The framework includes interaction with content, collaboration, conversation, intrapersonal interaction, and performance support. She first discusses the pedagogy used to promote the interaction and then a web-based software tool that allows the interactivity that is needed to support this. In this view, tools which fulfill the functions proposed in the framework increase the CSCL environment's interactivity and thus the level of interaction.

But building interactivity into web-based CSCL environments that includes support for collaborative learning does not mean that social interaction will occur. Just putting a forum in a group and labeling it 'café' or 'lobby' does not increase interaction. It is more important to focus on the actors or agents (group members, instructors, and content) who are to be involved in the social interaction and their needs. Building interactivity in (web-based) CSCL environments is necessary, since social interaction is- per definition- impossible without it, but is not sufficient. Interactivity enables educational techniques that stimulate collaboration and the development of a learning community to occur, but does not cause it.

\subsection{Changing the instructor's and/or learners' role in DLGs}

A third group has examined the ways instructors could play a (new) role in stimulating social interaction between group members in CSCL environments and/or how the members should socially interact within the group. Three factors drive this changing of roles, namely the shift from teacher-centered to learner-centered learning, the shift from individual learning to group learning, and the shift from contiguous learning groups to asynchronous distributed learning groups (the main focus in this article). While the first two shifts constitute a change in educational paradigms towards social construction of knowledge and competence-based learning, the last originates in the increased use of CSCL environments and has caught the prime attention of many (distance) educators.

Simonson (1995), for example, states that the instructor must strive "...to make the experience of the distance learner as complete, satisfying, and acceptable as that of the local learner" (p. 12). Burge (1994), in examining on-line courses, found four types of peer behaviors required in on-line collaborative learning, namely participation (e.g. giving alternative perspectives, attending to the experiences of others), response (e.g. giving constructive feedback, answering questions), affective feedback (e.g. using a person's name, being patient, complimenting others), and focused messaging. She also found two types of instructor behavior, namely discussion management (e.g. providing structure, pacing and focusing the class discussions), and contribution (e.g. giving fast and relevant technical help, sending timely and individualized content-related messages and feedback). 
Clark (2000) suggests that instructors initially start a discussion which students must continue on their own. This requires the instructor to relinquish control and avoid dominating the discussions. Many instructors find it difficult to make the transition from complete control of the classroom to unobstrusive monitoring.

\subsection{Increasing social presence in DLGs}

Finally, a group of educational researchers (e.g. Gunawardena, 1995; Gunawardena et al., 1997; Rourke, 2000a; Rourke et al., 1999; Tu, 2000) explain the lack of social interaction from a social presence theory perspective. Due to a lack of social presence, CMC hampers impression formation and thus the building of social relationships that are the basis of developing affective structures within the group. As a result, a social space and a sense of community are not likely to emerge. In such a context social interaction is impeded.

According to Gunawardena (1995), the development of social presence and a sense of community are the keys to promoting collaborative learning and knowledge building. Based upon empirical studies, she determined that social presence-the user's perception of the medium - can be cultivated through the creation of conducive learning environments, training participants how to create social presence, and building a sense of community, for example, through moderation. An example of this is having conference moderators facilitate discussions by recognizing all contributions initially, summarizing frequently, and weaving ideas together. This, however, requires instructors to learn to adapt their actions to the media used in order to develop relevant interaction skills. In her view, "it is these skills and techniques, rather than the medium, that will ultimately impact students' perception of interaction and social presence" (p. 165).

$\mathrm{Tu}$ (2000), linking social presence theory with social learning theories, states that social presence "is required to enhance and foster online social interaction, which is the major vehicle of social learning" (p. 27); "If social presence is low the foundation of social learning, social interaction, does not occur" (p. 30). He lists a number of factors that have been found to affect the degree of perceived social presence and categorized them in three dimensions, namely the social context, comprising elements such as task orientation, privacy, topics and social relationships, online communication, comprising elements such as communication anxiety, computer expertise and interactivity, emphasizing the potential for immediate feedback. These three dimensions should be considered "if one examines CMC as a learning environment or is applying student learning and socio-cultural learning to the CMC environment"' (p. 34).

\section{Summary, discussion and conclusions}

The utility of distributed learning groups for educational instruction is in vogue. Internet and new information and communication technologies has made this happen. Advanced CMC systems are developed and integrated in CSCL environments, 
thereby relaxing time and space. Educators, instructors and designers are in a hurry to unleash the potential of these CSCL environments for collaborative learning based on paradigms such the social construction of knowledge and competence based learning. But, despite the promises of contemporary CSCL environments, many studies still report disappointing results.

The key to the efficacy of collaborative learning is social interaction, and lack of it is a factor causing the negative effectiveness of collaborative learning. This lack of social interaction is due to the assumption that social interaction will automatically occur because the environment permits it and because the social interaction which is stimulated is usually restricted to the cognitive aspects of learning, ignoring/forgetting that social interaction is equally important for affiliation, impression formation, building social relationships and, ultimately, the development of a healthy community of learning. These are the issues that are difficult to achieve in CSCL environments and, therefore, need the special attention of educators, designers, and researchers. This article has discussed a number of educational techniques for avoiding these pitfalls.

However, we believe that all these educational techniques are just one part of a complete solution. The propensity to focus singularly on the cognitive aspects of learning has led to the design of purely functional CSCL environments, i.e. environments that solely support and guide social interaction towards critical thinking, argumentation, or socially constructing meaning. But, these functional CSCL environments forget that we are dealing with human beings. "People on the net are not only solitary information processors, but also social beings. They are not only looking for information; they are also looking for affiliation, support and affirmation. Thinking of people on the net as social actors evokes a metaphor of a gathering. Behaviors appropriate at the gathering include chatting, discussing, arguing, and confiding. People go to a gathering to find others with common interests and talk with or listen to them. When they find a gathering they like, they return to is again and again" (Sproull \& Faraj, 1997, p. 38).

For this reason we believe that another part of the solution lies in the design of sociable CSCL environments aimed at providing non-task contexts that allow social, off-task communication (e.g. casual communication) and that facilitate and increase the number of impromptu encounters in task and non-task contexts through the inclusion of persistent presence and awareness through time and space of the other members of the distributed learning group. Future research should, therefore, study approaches that guide the design of such sociable CSCL environments.

\section{References}

Aronson, E., Blaney, N., Stephan, G., Silkes, J., \& Snapp, M. (1978). The jigsaw classroom. Beverly Hills, CA: Sage Publications. 
Berge, Z. (1997). Computer conferencing and the on-line classroom. International Journal of Educational Telecommunications, 3(1), 3-21.

Brush, T. A. (1998). Embedding cooperative learning into the design of integrated learning systems: rationale and guidelines. Educational Technology Research and Development, 46(3), 5-18.

Burge, E. J. (1994). Learning in computer conferenced context: the learners' perspective. Journal of Distance Education, 9(1), 19-43.

Clark, J. (2000). Collaboration tools in online learning. ALN Magazine, 4(1). [Accessed 17 June, 2002]. Available: http://www.aln.org/alnweb/magazine/Vol4_issue1/Clark.htm.

Cockburn, A. \& Greenberg, S. (1993). Making contact: getting the group communicating with groupware. In Proceedings of the conference on organizational computing systems (COOCS '93) (pp. 31-41). Milpitas, CA: ACM Press.

Culnan, M. J., \& Markus, M. L. (1987). Information technologies. In F. M. Jablin, L. L. Putnam, K. H. Roberts, \& L. W. Porter (Eds.), Handbook of organizational communication: an interdisciplanary perspective (pp. 420-443). Newbury Park, CA: Sage.

Daft, R. L., \& Lengel, R. H. (1984). Information richness: a new approach to managerial behavior and organizational design. In B. M. Staw, \& L. L. Cummings (Eds.), Research in organizational behavior (Vol. 6) (pp. 191-233). Greenwich, CT: JAI.

Daft, R. L., Lengel, R. H., \& Trevino, L. (1987). Message equivocality, media selection, and manager performance. MIS Quaterly, 11(3), 355-366.

Emans, B., Koopman, P., Rutte, C., \& Steensma, H. (1996). Teams in organisaties: interne en externe determinanten van resultaatgerichtheid [Teams in organizations: Internal and external determinants of result focus]. Gedrag en Organisatie, 9(6), 309-327.

Fishman, B. J. (1997). Students traits and the use of computer-mediated communication tools: what matters and why? Paper presented at the 1997 AERA Annual Meeting, Chicago, IL.

Forsyth, D. R. (1990). Group dynamics (2nd ed.). Belmont: Brooks \& Cole.

Garrison, D. R. (1993). Quality and theory in distance education: theoretical consideration. In D. Keegan (Ed.), Theoretical principles of distance education. New York: Routledge.

Garrison, D. R., Anderson, T., \& Archer, W. (2001). Critical thinking and computer conferencing: a model and tool to access cognitive presence. American Journal of Distance Education, 15(1), 7-23.

Garton, L., \& Wellman, B. (1995). Social impacts of electronic mail in organizations: a review of the research literature. In B. R. Burleseon (Ed.), Communication yearbook (Vol. 18) (pp. 438-453). Thousand Oaks, CA: Sage.

Gilbert, L., \& Moore, D. R. (1998). Building interactivity into web courses: tools for social and instructional interaction. Educational Technology, 38(3), 29-35.

Gilroy, K. (2001). Collaborative E-learning: the right approach. ArsDigita Systems Journal. Availble: http://www.arsdigita.com/asj/elearning/ [accessed 17 June 2002].

Gunawardena, C. N. (1995). Social presence theory and implications for interaction and collaborative learning in computer conferences. International Journal of Educational Telecommunications, 1(2/3), 147166.

Guanawardena, C. N., Lowe, X., Constance, A., \& Anderson, T. (1997). Analysis of a global debate and the development of an interaction analysis model for examining social construction of knowledge in computer conferencing. Journal of educational computing research, 17(4), 397-431.

Hallet, K., \& Cummings, J. (1997). The virtual classroom as authentic experience. In Proceedings of the Annual Conference on Distance Teaching and Learning: Competition-Connection-Collaboration (pp. 103-107). Madison, WI: University of Wisconsin-Madison.

Hiltz, S. R. (1994). The virtual classroom: learning without limits via computer networks. Norwood, NJ USA: Ablex Publishing Corporation.

Hiltz, S. R. (1997). Impacts of college-level courses via asynchronous learning networks: some preliminary results. Journal of Asynchoronous Learning Networks, 1(2). Available: http://www.aln.org/alnweb/journal/issue2/hiltz.htm [accessed 17 June 2002].

Hiltz, S. R. (1998). Collaborative learning in asynchronous learning networks: building learning communities. Invited Address at "WEB98", Orlando, FL. Available: http://eies.njit.edu/ hiltz/collaborative_learning_in_asynch.htm [accessed 17 June 2002]. 
Hiltz, S. R., Johnson, K., \& Turoff, M. (1986). Experiments in group decision making: communication process and outcome in face-to-face versus computerized conferences. Human Communication Research, $13,225-252$.

Hobaugh, C. F. (1997). Interactive strategies for collaborative learning. In Proceedings of the Annual Conference on Distance Teaching and Learning: Competition-Connection-Collaboration (pp. 121-125). Madison, WI: University of Wisconsin-Madison.

Hooper, S., \& Hannafin, M. J. (1991). The effects of group composition on achievement, interaction, and learning efficiency during computer-based cooperative instruction. Educational Technology Research and Development, 39(3), 27-40.

Jehng, J. J. (1997). The psycho-social processes and cognitive effects of peer-based collaborative interactions with computers. Journal of Educational Computing Research, 17(1), 19-46.

Johnson, D. W., \& Johnson, R. T. (1979). Conflict in the classroom: controversy and learning. Review of Educational Research, 49, 51-70.

Johnson, D. W., \& Johnson, R. T. (1989). Cooperation and learning: theory and research. Edina, MN: Interaction Book Company.

Johnson, D. W., \& Johnson, R. T. (1993). Creative and critical thinking through academic controversy. American behavioral scientist, 37(1), 40-53.

Johnson, D. W., \& Johnson, R. T. (1999). Learning together and alone: cooperative, competitive, and individualistic learning (5th ed.). Boston: Allyn \& Bacon.

Johnson, R. T., Johnson, D. W., \& Stanne, M. B. (1985). Effects of cooperative, competitive, and individualistic goal structures on computer-assisted instruction. Journal of Educational Psychology, 77(6), 668-677.

Jonassen, D. H. (1991). Context is everything. Educational Technology, 31(6), 35-37.

Jonassen, D. H. (1994). Toward a constructivist design model. Educational Technology, 34(4), 34-37.

Kearsley, G. (1995). The nature and value of interaction in distance learning. (ACSDE Research Monograph No. 12). State College, Pennsylvania: Pennsylvania State University, American Center for the Study of Distance Education.

Keen, K. (1992). Competence: what is it and how can it be developed? In J. Lowyck, P. de Potter, J. Elen (Eds.), Instructional design: implementation issues (pp. 111-122). Brussels, Belgium: IBM Education Center.

Kerr, N. (1983). The dispensability of member effort and group motivation losses: free-rider effects. Journal of Personality and Social Psychology, 44, 78-94.

Kerr, N., \& Bruun, S. (1983). The dispensability of member effort and group motivation losses: free-rider effects. Journal of Educational Computing Research, 5, 1-15.

Kiesler, S., Siegel, J., \& McGuire, T. W. (1984). Social psychological aspects of computer-mediated communication. American Psychologist, 39, 1123-1134.

Kirschner, P. A. (2001). Using integrated electronic environments for collaborative teaching/learning. Research Dialogue in Learning and Instruction, 2(1), 1-10.

Kirschner, P. A., van Vilsteren, P., Hummel, H., \& Wigman, M. (1997). A study environment for acquiring academic and professional competence. Studies of Higher Education, 22(2), 151-171.

Latané, B., Williams, K., \& Harkins, S. (1979). Many hands make light the work: the causes and consequences of social loafing. Journal of Personality and Social Psychology, 37, 822-832.

Lethinen, E., Hakkarainen, K., Lipponen, L., Rahikainen, M., \& Muukkonen, H. (1999). Computer supported collaborative learning: a review. CL-Net Project. Available: http://www.kas.utu.fi/clnet/clnetreport.html [accessed 17 June 2002].

Liaw, S., \& Huang, H. (2000). Enhancing interactivity in web-based instruction: a review of the literature. Educational Technology, 40(3), 41-45.

McConnell, D. (1994). Implementing computer supported cooperative learning. London: Kogan Page Limited.

McCroskey, J. C. (1977). Oral communication apprehension: a summary of recent theory and research. Human Communication Research, 4, 78-96.

Morrison, D., \& Collins, A. (1996). Epistemic fluency and constructivist learning environments. In B. Wilson (Ed.), Constructivist learning environments (pp. 107-119). Englewood Cliffs: Educational Technology Press. 
Muirhead, B. (1999). Attitudes toward interactivity in a distance education program: a qualitative analysis. Parkland, FL: Dissertation.com.

Northrup, P. (2001). A framework for designing interactivity in web-based instruction. Educational Technology, 41(2), 31-39.

Ohlsson, S. (1996). Learning to do and learning to understand: a lesson and a challenge for cognitive modeling. In P. Reimann, \& H. Spada (Eds.), Learning in humans and machines (pp. 37-62). Oxford: Pergamon.

Olson, G. M., \& Olson, J. S. (2000). Distance matters. Human Computer Interaction, 15, 139-178.

Panitz, T. (1996). Collaborative versus cooperative learning. Available http://ericae.net/k12assess/colcoo.htm [accessed 17 June 2002].

Rice, R. E. (1992). Contexts of research on organizational computer-mediated communication. In M. Lea (Ed.), Contexts of computer-mediated communication (pp. 113-144). London: Harvester Wheatsheaf.

Rice, R. E. (1993). Media appropriateness: using social presence theory to compare traditional and new organizational media. Human Communication Research, 19, 451-484.

Roschelle, J., \& Teasley, S. (1995). The construction of shared knowledge in collaborative problem solving. In C. O’Malley (Ed.), Computer-supported collaborative learning (pp. 69-97). New York: SpringerVerlag.

Rourke, L. (2000a). Exploring social communication in computer conferencing. Unpublished Master Thesis. Alberta, Edmonton Alberta.

Rourke, L. (2000b). Operationalizing social interaction in computer conferencing. In Proceedings of the 16th Annual conference of the Canadian Association for Distance Education. Quebec City. Available: http://www.ulaval.ca/aced2000cade/english/proceedings.html [accessed 31 January, 2001].

Rourke, L., Anderson, T., Archer, W., \& Garrison, D. R. (1999). Assessing social presence in asynchronous text-based, computer conferencing. Journal of Distance Education, 14(3), 51-70.

Rovai, A. P. (2001). Classroom community at a distance: a comparative analysis of two ALN-based university programs. Internet and Higher Education, 4, 105-118.

Short, J., Williams, E., \& Christie, B. (1976). The social psychology of telecommunications. London: John Wiley \& Sons, Ltd.

Sharan, S., \& Sharan, Y. (1976). Small group teaching. Englewood Cliffs, NJ: Educational Technology Publications.

Sharan, Y., \& Sharan, S. (1992). Expanding cooperative learning through group investigation. New York: Columbia University.

Simonson, M. (1995). Does anyone really want to learn... at a distance. TechTrends, 40(5), 12.

Slavin, R. E. (1986). Using student team learning (3rd ed.). Baltimore, MD: Center for Social Organization of Schools, The Johns Hopkins University.

Slavin, R. E. (1990). Cooperative learning. Review of Educational Research, 50(2), 315-342.

Slavin, R. E. (1997). Educational psychology: theory and practice (5th ed.). Needham Heights, MA: Allyn \& Bacon.

Soller, A. L. (1999). Supporting social interaction in an intelligent collaborative learning system. Unpublished Master Thesis.

Soller, A. L., \& Lesgold, A., Linton, F., Goodman, B. (1999). What makes peer interaction effective? Modeling effective communication in an intelligent CSCL. In Proceedings of the 1999 AAAI Fall Symposium: Psychological Models of Communication in Collaborative Systems (pp. 116-123). Cape-Cod, MA.

Sproull, L., \& Faraj, S. (1997). Atheism, sex, and databases: the net as a social technology. In S. Kiesler (Ed.), Culture of the internet (pp. 35-52). Mahwah, NJ: Lawrence Erlbaum and Assocs.

Sproull, L., \& Kiesler, S. (1986). Reducing social context cues: electronic mail in organizational communication. Management Science, 32, 1492-1512.

Tu, C. H. (2000). On-line learning migration: from social learning theory to social presence theory in a CMC environment. Journal of Network and Computer Application, 23(1), 27-37.

Van der Linden, J., Renshaw, P. (Eds.). (2001). Dialogic learning. Dordrecht: Kluwer Academic Publishers.

Wagner, E. D. (1994). In support of a functional definition of interaction. The American Journal of Distance Education, 8(2), 6-29. 
Wagner, E. D. (1997). Interactivity: from agents to outcomes. New Directions for Teaching and Learning, 71, 19-26.

Walther, J. B. (1992). Interpersonal effects in computer-mediated interaction: a relational perspective. Communication Research, 19(1), 52-90.

Walther, J. B. (1993). Impression development in computer-mediated interaction. Western-Journal of Communication, 57, 381-398.

Walther, J. B. (1996). Computer-mediated communication: impersonal, interpersonal, and hyperpersonal interaction. Communication Research, 23(1), 3-43.

Walther, J. B., Anderson, J. F., \& Park, D. (1994). Interpersonal effects in computer-mediated interaction: a meta-analysis of social and anti-social communication. Communication Research, 19, 460-487.

Wegerif, R. (1998). The social dimension of asynchronous learning networks. Journal of Asynchronous Learning Networks, 2(1), 34-49.

Zhang, S., \& Fulford, C. P. (1994). Are interaction time and psychological interactivity the same thing in the distance learning television classroom. Educational Technology, 34(6), 58-64. 